\title{
Autoriti Agama di Malaysia: Kedudukan dan Kritikan
}

\author{
Religious Authority in Malaysia: Position and Criticism
}

NUR FARHANA ABDUL RAHMAN* \& NUR SOLEHAH SHAPIEE1

\begin{abstract}
The purpose of this study is to highlight the view of G25 towards the religious authority in Malaysia. G25 is seen to have its own definitions pertaining to Islamic religious authority which has led this group to voice out several issues and criticism towards religious authority. These issues and criticism have caused some controversy and confusion among Muslim communities in Malaysia. Hence, this study aims to analyze the views and key issues raised by G25 about religious authority and their justification. This is qualitative study using content analysis methodology from various sources in the form of books, journals, articles and electronic materials related to this topic and supported by the interview with one of their members in elaborating their views on the issues. The findings show that G25 claimed that they are not rejecting religious authority completely but rejects the approach of the procedure used by religious authority in implementing Syariah Law. In view of that, G25 demands that the implementation of Syariah Law must be accordance with the Federal Constitution, which they believe it is secular. Hence, the interpretation of the texts of the Holy Qur'an and the Sunnah as the basis of lawmaking especially regarding of Syariah Laws should be re-examined in the method of interpretation.
\end{abstract}

Keywords: Islam and liberalism, Islam in Malaysia, liberalism, religious affairs, religious authority

Umum mengetahui bahawa agama adalah pegangan dan asas kehidupan seseorang. Oleh itu, bagi sesebuah negara yang meletakkan agama dalam perlembagaannya sebagaimana Malaysia yang menjadikan Islam sebagai agama Persekutuan, pastinya mempunyai institusi dan jabatan tertentu dalam mengawal selia hal ehwal Islam dan masyarakat Muslim di Malaysia. Dalam memahami, mempelajari dan mempraktikkan amalan agama Islam, pastinya wujud perbezaan pendapat dan pandangan serta aliran dalam menginterpretasikan makna disebalik sumber wahyu seperti al-Quran dan Hadis. Namun, dengan adanya panduan fatwa dan ijma', segala pentafsiran dan pemahaman ke atas wahyu dapat diselarikan dengan pegangan Ahli Sunnah Waljamaah. Mutakhir ini, munculnya beberapa kelompok dan aliran yang datang dengan pembawaan kefahaman Islam yang berlainan dari arus kebiasaan serta mempunyai pendefinisian dan interpretasinya tersendiri khususnya berkaitan pelaksanaan agama dan undang-undang Islam.

\footnotetext{
${ }^{1}$ Nur Farhana Abdul Rahman*(corresponding author), Ph.D., senior lecturer at Centre of Aqidah and Global Peace, Faculty of Islamic Studies, Universiti Kebangsaan Malaysia, 43600 BANGI, Selangor, Malaysia, email: nfarhana@ukm.edu.my; Nur Solehah Shapiee, M.A. candidate at Centre of Aqidah and Global Peace, Faculty of Islamic Studies, Universiti Kebangsaan Malaysia, 43600 BANGI, Selangor, Malaysia, email: p93063@siswa.ukm.edu.my.
} 


\section{Permasalahan Kajian}

Mutakhir ini pelbagai isu berkaitan agama Islam dilaungkan dan diperjuangkan oleh pelbagai pihak dan kelompok masyarakat. Mereka memperjuangkan hak asasi dan kebebasan manusia bahawa amalan beragama dan perkara-perkara yang berkaitan dengannya merupakan urusan individu tanpa memerlukan kepada seliaan dan keterikatan dengan mana-mana autoriti dan institusi agama. Muncul pelbagai kelompok yang mula mempersoalkan kredibiliti institusi agama Islam serta huraian terhadap sumber ilmu agama Islam di Malaysia. Namun, masalah pokok bagi hal ini apabila sebahagian penentangan dan pertikaian yang dilakukan bukanlah datang daripada golongan bukan Islam tetapi daripada kelompok umat Islam sendiri. Menurut Marzuki (2009: 160) bermula pertengahan tahun 1990-an, golongan liberal dalam masyarakat Islam di Malaysia telah mula mengkritik pelaksanaan undang-undang keluarga dan jenayah Islam yang mereka lihat bertentangan dengan prinsip-prinsip hak asasi manusia dan bersifat diskriminatif terhadap wanita dan bermula pada awal tahun 2000, golongan ini telah mula mewujudkan gabungan persatuan dan pertubuhan yang sama-sama bertujuan memperjuangkan hak asasi manusia, menentang pelaksanaan undang-undang Islam dan undang-undang kecil kerajaan tempatan yang mencegah perlakuan maksiat dan kurang sopan yang dianggap bertentangan dengan hak asasi manusia dan kebebasan individu. Perjuangan mencabar kelaziman kuasa agama yang memainkan peranan dalam pentadbiran negara dan penelitian semula konteks-konteks agama ini sebenarnya dipengaruhi oleh idea liberal dan sekular dari Barat yang mempromosikan pengasingan pengaruh agama dalam kuasa pemerintahan lebih-lebih lagi dalam arus moden masa kini. Oleh itu, idea liberal dan sekular ini memperjuangkan agar agama disesuaikan mengikut keadaan dan tuntutan zaman.

Dalam konteks Malaysia, antara kumpulan umat Islam yang bangun memperjuangkan agar autoriti agama Islam di Malaysia diteliti semula dikenali sebagai Kumpulan G25. Kumpulan G25 ini mengemukakan beberapa tuntutan yang mana tuntutan-tuntutan tersebut telah menimbulkan kontroversi dan dianggap mencabar kredibiliti agama Islam dan kuasa autoritinya di Malaysia. Kritikan dan serangan ke atas autoriti agama melalui tuntutan penelitian semula hak autoriti agama dikalangan pihak berkuasa atau pemimpin agama jelas kelihatan dalam perjuangan mereka ke atas beberapa isu berkaitan autoriti dan undang-undang agama Islam. Antara isu-isunya adalah seperti berikut:

1. Rang Undang-Undang 355: Dari perspektif G25, kumpulan ini menolak agar RUU 355 dilaksanakan dengan beralasan bahawa bidang kuasa mahkamah syariah terhad dalam Perlembagaan Persekutuan dan usaha meninggikan taraf mahkamah syariah akan mencelarukan penguatkuasaan dan menimbulkan kekeliruan terhadap pelaksanaan undang-undang mahkamah sivil dengan mahkamah syariah (G25 2017: 1).

2. Pemansuhan Hukuman Khalwat: Kumpulan G25 menuntut agar hukuman khalwat dimansuhkan kerana dianggap telah mencerobohi hak privasi individu. Tambahan lagi, mereka juga turut bercadang untuk menubuhkan sebuah jawatankuasa perunding yang bertujuan meminda dan memansuhkan beberapa lagi hukum-hukum syariah yang dianggap tidak releven (Rodelio 2015: 6). Menurut Mariam, seorang kolumnis dalam akhbar Free Malaysia Today menyatakan bahawa Kumpulan G25 juga berpendirian bahawa hukum Hudud bukanlah hukum Allah SWT dan kewujudan autoriti agama terhadap kehidupan orang Islam dilihat sebagai satu bentuk ekstrimisme (Religious Extrimisme) (Mariam 2015: 1). Selain itu, G25 juga turut menuntut agar Jabatan Kemajuan Islam Malaysia (JAKIM) dimansuhkan dan akaunnya diaudit semula (Mohamad 2015: 1). 
Secara konklusinya dapat difahami bahawa disebalik isu dan tuntutan yang dikemukakan oleh G25 jelas menggambarkan bahawa mereka mempunyai pandangan dan tafsiran lain berkaitan peranan dan pelaksanaan autoriti agama Islam di Malaysia. Meskipun begitu, mereka menegaskan bahawa tuntutan ke atas perbahasan secara rasional dan ilmiah tentang undangundang Islam di Malaysia dan penelitian semula itu bukanlah berbentuk satu penghinaan terhadap Islam dan pihak berkuasa agama di negara ini (G25 2014: 1). Isu dan tuntutan yang dikemukakan oleh mereka telah menimbulkan kontroversi serta dianggap menggugat kedaulatan agama Islam di Malaysia. Rentetan daripada hal ini, kajian bertujuan mengenalpasti apakah definisi dan pandangan sebenar yang dimaksudkan oleh G25 disebalik tuntutan-tuntutan tersebut terhadap autoriti agama Islam di Malaysia? Apakah pula faktor yang menyebabkan munculnya tuntutan-tuntutan yang dikeluarkan oleh G25 sehingga dianggap mencabar autoriti agama di Malaysia? Justeru itu, kajian ini akan mengkaji dan mengenalpasti kritikan-kritikan yang dilontarkan oleh G25 ke atas autoriti agama beserta justifikasinya.

\section{Metodologi Kajian}

Rekabentuk kajian adalah kualitatif dengan menggunakan kaedah pengumpulan data secara dokumen dan temubual.

1. Analisis Kandungan: Metod analisis ini dilakukan terhadap maklumat-maklumat dan penulisan kumpulan G25 dan golongan yang membawa idea yang sama seperti mereka berkaitan autoriti agama, Islam Liberal dan Hak Asasi Manusia. Kaedah ini turut melibatkan metod perbandingan terhadap data-data yang diperolehi. Antara bahan kajian dan dokumen yang dianalisis termasuk laman web rasmi G25, buku, jurnal, akhbar, kertas kerja, tesis, projek ilmiah dan lain-lain. Laman web dan senarai teks oleh G25.

2. Kaedah Temubual; Kaedah temubual yang digunakan ialah temubual separa berstruktur terhadap dua orang pakar. Seorang pakar daripada G25 dan seorang pakar lagi daripada undang-undang Islam. Temubual pengkaji bersama salah seorang ahli G25 telah ditentukan oleh kumpulan G25 sendiri bagi mewakili pandangan mereka untuk kajian ini.

3. Kaedah Analisis Data: Data kajian ini dianalisis secara deskriptif dan tematik. Data temubual pula dianalisis secara transkripsi verbatim.

\section{Kedudukan Autoriti Agama di Malaysia}

Autoriti agama merupakan satu badan berkuasa yang memperuntukkan undang- undang berkaitan hal ehwal agama Islam dibawah naungan Sultan dalam sistem demokrasi berperlembagaan negara Malaysia yang menjadikan agama Islam sebagai agama persekutuan disamping agama-agama lain boleh diamalkan dengan aman dan damai di mana-mana bahagian Persekutuan. Undang-undang negara ini juga telah memartabatkan Islam sebagai Agama Negara dalam Fasal 1 Perkara 3 Perlembagaan Persekutuan (Mahamad n.d.: 1- 7). Manakala, dalam sudut kebebasan beragama juga turut dihuraikan dalam Perkara 11 Perlembagaan Malaysia yang mengandungi isi kandungan seperti berikut:

Tiap-tiap orang berhak menganuti dan mengamalkan agamanya dan, tertakluk kepada Fasal (4), mengembangkannya.

(1) Tiada seorang pun boleh dipaksa membayar apa-apa cukai yang hasilnya diuntukkan khas kesemuanya atau sebahagiannya bagi maksud sesuatu agama selain agamanya sendiri. 
(2) Tiap-tiap kumpulan agama berhak:

a. Menguruskan hal ehwal agamanya sendiri

b. Menubuhkan dan menyenggarakan institusi-institusi bagi maksud agama atau khairat dan

c. Memperoleh dan mempunyai harta dan memegang dan mentadbirkannya mengikut undang-undang.

(3) Undang-undang Negeri dan berkenaan dengan Wilayah-Wilayah Persekutuan Kuala Lumpur, Labuan dan Putrajaya, undang- undang persekutuan boleh mengawal atau menyekat pengembangan apa-apa doktrin atau kepercayaan agama di kalangan orang yang menganuti agama Islam.

(4) Perkara ini tidaklah membenarkan apa-apa perbuatan yang berlawanan dengan mana-mana undang-undang am yang berhubungan dengan ketenteraman awam, kesihatan awam atau prinsip moral.

Bertitik tolak daripada hal ini, tiga institusi agama yang utama diwujudkan bagi menjaga dan menyelia maslahah dan urusan umat Islam di Malaysia iaitu Majlis Agama Islam, Mufti dan Mahkamah Syariah (Abdul 2009: 5). Daripada tiga institusi utama ini, lahirlah pelbagai jabatan, lembaga, institut dan persatuan Islam sama ada dibawah seliaan kerajaan ataupun persendirian. Misalnya seperti Jabatan Kemajuan Islam Malaysia (JAKIM), Institut Kefahaman Islam Malaysia (IKIM), Lembaga Tabung Haji, Lembaga Zakat, Jabatan Agama Islam mengikut negeri-negeri di Malaysia dan sebagainya. Melalui tiga institusi utama agama yang disebutkan sebelum ini, hukum-hakam dan perundangan Islam digubal dan dilaksanakan di Malaysia. Kedudukan Islam sebagai agama persekutuan negara Malaysia turut menjadikan ajaran Islam sebagai teras kepada pembentukan falsafah dan ideologi negara (Nazri\&Ahmad n.d.: 120). Maka, secara tidak langsung menolak tohmahan dan dakwaan bahawa Malaysia adalah sebuah negara sekular dan liberal. Sebagaimana menurut Mahamad (n.d. 7) dalam artikelnya yang menjelaskan bahawa kedudukan agama Islam adalah lebih tinggi daripada perlembagaan dengan menyatakan:

Kedudukan agama Islam yang tinggi di Malaysia menjadikan autoriti agama Islam mesti dihormati dan dipatuhi sebagai undang-undang tertinggi Negara. Sebarang dasar dan undang-undang yang digubal mestilah tidak bercanggah dengan agama Negara dan memelihara ketinggiannya adalah menjadi kewajipan pemerintah. Justeru itu, pihak pemerintah hendaklah sentiasa memastikan segala bentuk dasar dan undang-undang yang bercanggah dengan Islam hendaklah diperbetulkan bagi memastikan ia adalah selaras dengan agama Negara dan seterusnya meletakkan Islam itu di tempat yang sepatutnya.

Berdasarkan kepada hal ini, dapatlah diketahui bahawa kedudukan agama Islam sebagai agama persekutuan berperanan dalam pelaksanaan undang-undang negara dan kehidupan masyarakat Muslim serta memberi gambaran jelas bahawa autoriti agama Islam mempunyai pengaruh dan kuasa dalam menyelia hal ehwal kebajikan umat Islam, memelihara sumbersumber ilmu agama Islam dan hal-hal berkaitan pendidikan Islam dan sebagainya. Dalam masa yang sama, adanya undang- undang sivil yang menjaga hak dan kebajikan awam keseluruhan masyarakat sama ada Islam dan bukan Islam di Malaysia.

\section{Kritikan ke atas Autoriti Agama dan Justifikasinya}

Kumpulan G25 telah ditubuhkan pada 7 Disember 2014 oleh sekumpulan Melayu Muslim yang kebanyakannya terdiri daripada pesara penjawat awam, ahli professional dan ahli akademik 
yang dianggotai oleh 25 orang ahli pada permulaannya dan menamakan kumpulan mereka sebagai Group of 25, G25 (G25 2016: 13). Namun, jumlah ahli G25 semakin bertambah dan telah melebihi daripada 25 orang, lalu mereka memutuskan untuk mengekalkan nama G25 tersebut kerana nama ini telah sinonim dan lebih dikenali dalam masyarakat awam di Malaysia (G25 2016: 16)

Secara umumnya, satu surat terbuka telah dikeluarkan oleh kumpulan G25 sendiri kepada seluruh rakyat Malaysia yang ditulis di laman web mereka yang bertajuk Champion Open Debate and Discourse on Islamic Law pada tahun 2014. Dalam surat terbuka ini G25 menyatakan kekecewaannya terhadap pelaksanaan undang-undang dan syariat Islam di Malaysia yang dilihat banyak mendiskriminasi hak asasi manusia dan bersifat ekstrim. Oleh itu, mereka menyeru rakyat Malaysia untuk mengadakan sebuah debat terbuka untuk membincangkan dan memurnikan segala persoalan dan kekacauan yang berlaku dalam pentadbiran dan autoriti agama Islam di Malaysia. Antara isu yang yang menjadi kritikan mereka adalah berkaitan penyataan yang dikeluarkan oleh Datuk Seri Jamil Khir Baharom berkaitan respon terhadap keputusan mahkamah ke atas hak golongan transgender untuk berpakaian mengikut identiti yang mereka pilih dan beliau juga turut menggelarkan isu itu sebagai satu serangan gelombang baru ke atas Islam (New Wave of Assault on Islam). G25 dalam suratnya berpendapat bahawa kenyataan tersebut adalah satu kenyataan yang kasar dan tidak menggambarkan nilai kesederhanaan dan wasatiyyah dalam Islam. Bertitik tolak daripada hal ini, dalam surat tersebut kumpulan G25 mula menyatakan tuntutan dan saranan daripada pihaknya kepada kerajaan Malaysia yang dilihat dapat membantu memperbaiki sistem dan pelaksanaan undang-undang Islam di Malaysia agar Islam dapat diamalkan dengan sederhana dan harmoni serta dinikmati oleh semua orang (G25 2014: 1).

Selain itu, G25 juga turut menghasilkan sebuah dokumen ringkasan hasil daripada forum yang bertajuk Islam in A Constitutional Democracy pada tahun 2016 anjuran G25 sendiri yang dibentangkan oleh 19 panel jemputan. Dalam forum tersebut, memfokuskan lima topik utama berkaitan Islam iaitu Perlembagaan Persekutuan dan Syariah Undang-undang, Isu konflik dan pertindihan antara Undang- Undang Sivil Dan Undang-Undang Syariah, Islamisasi dan akibatnya, Islam dan Politik serta Maqasid al-Syariah dan Wasatiyyah. Sebagaimana yang diketahui bahawa Malaysia mempunyai dua mahkamah undang-undang iaitu Mahkamah Sivil secara umumnya dan Mahkamah Syariah yang khusus untuk orang Islam. G25 melihat kewujudan dua jenis mahkamah undang-undang serentak menggambarkan wujudnya dua sistem undang-undang dalam negara. Hal ini menyebabkan berlakunya percanggahan bidang kuasa dan dilema dalam beberapa isu seperti hak penjagaan dan penukaran unilateral untuk kanak-kanak. Tambahan lagi, mereka turut menyatakan rasa tidak berpuas hati kepada pegawai-pegawai penguatkuasa Syariah yang dianggap berlebih-lebihan dalam bertugas dan tindakan autoriti agama seperti ini mengancam hak asasi manusia dan kebebasan awam rakyat negara ini (G25 2016: 5).

Seterusnya, dalam buku keluaran G25 yang bertajuk Breaking the Silence: Voices of Moderation telah menghimpunkan penulisan oleh 21 orang ahli akademik dalam membincangkan hal ehwal perundangan Islam di Malaysia. Antara penulisan dalam buku tersebut adalah berkaitan Kebebasan Asasi dalam Perlembagaan Persekutuan (Fundamental Liberties in Federal Constitution). Menurut Azmi (2016: 95-96), Perlembagaan Malaysia berkaitan Perkara 5: Kebebasan Diri (Liberty of The Person) menjelaskan bahawa kebebasan individu yang termaktub dalam Perlembagaan Persekutuan mempunyai maksud yang lebih luas dan tidak terhad kepada kebebasan hak untuk hidup dan melindungi seseorang daripada dibunuh dan dipenjarakan tanpa hak semata-mata. Tetapi, seseorang itu juga bebas dan berhak untuk memilih gaya hidup tersendiri dalam mencapai matlamat dan kualiti kehidupan yang diinginkan. Perkara ini boleh dilihat dalam pengurusan isu Transgender. Menurut beliau, dengan menjadikan tindakan lelaki berpakaian wanita dan sebaliknya untuk golongan yang mempunyai Gender Identity Disorder (GID) sebagai suatu kesalahan, sebagaimana yang ditetapkan oleh Enakmen Syariah Negeri Sembilan sebenarnya telah menafikan hak mereka untuk bergerak bebas dan 
memberikan implikasi dalam kebebasan individu untuk menjalani kehidupan harian seperti biasa, keluar rumah dan bekerja. Hal ini juga dilihat oleh beliau bertentangan dengan Perkara 5 dalam perlembagaan. Selain itu, dalam penulisannya juga turut menyentuh Perkara 11, Kebebasan Beragama (Freedom of Religion) yang mana menurut beliau meskipun penyebaran agama lain kepada orang Islam adalah terbatas, tetapi tidak sepatutnya ada halangan dalam kebebasan memilih agama mereka sebagaimana yang telah dilaksanakan oleh kebanyakan negeri bahawa tindakan keluar daripada Islam (murtad) adalah satu jenayah dan kesalahan. Jelasnya daripada hal ini menunjukkan kebebasan beragama untuk orang Islam tidak dilindungi dan undang-undang yang tidak beperlembagaan ini tidak di atasi dengan baik dan dilihat bertentangan dengan Perkara 11 tersebut (Azmi 2016 :101). Beliau berpandangan bahawa orang Islam turut mempunyai hak untuk keluar dari agama Islam dan memilih agama lain yang mereka mahukan.

Rentetan daripada perkara ini, kritikan-kritikan G25 ke atas autoriti agama dan justifikasinya diperincikan seperti berikut:

\section{Penentangan Terhadap Rang Undang-Undang 355 (RUU 355)}

G25 memberi respon untuk menolak pelaksanaan Rang Undang-Undang 355 (RUU 355) yang dibahaskan. Oleh itu, G25 telah menyenaraikan beberapa hujah penolakan mereka terhadap usaha pelaksanaan RUU 355 oleh mahkamah Syariah di Malaysia seperti berikut (G25 2017: 1):

1. Berdasarkan Perkara 4 Perlembagaan menunjukkan bahawa bidang kuasa mahkamah syariah adalah terhad dalam Perlembagaan Persekutuan. Jadual Kesembilan Senarai Negeri Item 1, berkaitan bidang kuasa mahkamah syariah ke atas penghukuman kesalahan telah menyatakan bahawa adanya kuasa meletakkan hukuman ke atas orangorang Islam tetapi bidang kuasa tersebut adalah terhad setakat yang diberikan oleh undang-undang Persekutuan. Tujuan peruntukan ini supaya Parlimen dapat mengawasi pelaksanaan penghukuman kesalahan, termasuk tatacara penghukuman yang dirangka oleh enakmen negeri agar Badan Perundangan Negeri tidak terbuka untuk memperuntukkan penghukuman kesalahan serta menjatuhkan hukuman.

2. Pelaksanaan RUU355 akan meninggikan taraf mahkamah Syariah dan hal ini akan menyebabkan kecelaruan dalam penguatkuasaan undang-undang negara dan perintahperintah tetap.

3. Kesan daripada RUU 355 juga dilihat akan menjauhkan pelabur perniagaan asing dan memberi kesan kepada ekonomi negara. Hal ini kerana, jika negara melangkah ke arah sistem perundangan Islamik radikal maka Malaysia akan dipandang sebagai keras dan tidak progresif sehala dengan nilai-nilai kehidupan moden.

4. RUU355 dilihat sebagai satu batu loncatan menuju kepada pelaksanaan hukuman hudud. Menurut G25 walaupun para penyokong PAS tegas menafikan bahawa pindaan RUU355 bertujuan untuk melaksanakan undang- undang hudud, tetapi penafian ini diragui kerana negeri Kelantan di bawah kerajaan PAS sudah pun meluluskan Rang Undang-undang Kanun Jenayah Syariah II (1993) 2015. Rang Undang-undang Negeri Kelantan ini memperuntukkan hukuman hudud untuk kesalahan-kesalahan seperti zina, mencuri, merompak, liwat, minum arak dan murtad.

5. G25 menyeru kerajaan untuk lebih memberi fokus kepada penambahbaikan urus tadbir kerajaan dan institusi awam ke arah yang lebih berkualiti dan bermanfaat serta mencari jalan penyelesaian untuk membasmi kemiskinan dan membela hak orang-orang yang kurang bernasib baik untuk kemajuan ekonomi dan sosial negara. Bahkan perkara ini dilihat lebih Islamik daripada pelaksanaan hudud. 
Penentangan G25 ke atas isu RUU 355 untuk dipinda adalah kerana mereka menyokong pandangan bahawa Malaysia adalah negara sekular. Justifikasinya berdasarkan petikan kata-kata Tunku Abdul Rahman yang menyebut bahawa Malaysia adalah negara sekular. Kontrak sosial yang telah dipersetujui dan dirunding oleh Tunku Abdul Rahman bersama ahli-ahli Perikatan, Sultan dan British daripada mula lagi bertujuan untuk menjadi Perlembagaan sekular dan tidak pernah dimaksudkan untuk menjadi sebuah Perlembagaan Islam. Oleh itu, G25 berpendirian bahawa Malaysia merupakan sebuah negara sekular bermula ketika zaman kemerdekaan lagi dan mereka berpendapat bahawa pelaksanaan RUU 355 iaitu satu proses kepada pengukuhan undang-undang Syariah hanya akan mengubah negara Malaysia yang asalnya adalah bersifat sekular kepada sebuah proses Islamisasi dalam perlembagaan khususnya berkaitan hukum hudud (G25 2017: 1).

\section{Pertentangan Antara Mahkamah Sivil Dan Mahkamah Syariah}

G25 melihat kewujudan dua mahkamah utama dalam satu negara telah menyebabkan berlakunya pertindihan dan pertentangan (overlapping) iaitu antara mahkamah Syariah dan mahkamah Sivil. Oleh itu, G25 berhujah bahawa Perkara 4 Perlembagaan Persekutuan telah menetapkan bahawa status Perlembagaan Persekutuan, undang- undang persekutuan dan mahkamah Sivil adalah lebih tinggi daripada enakmen undang-undang syariah negeri dan hal ini penting demi memastikan hanya wujud satu sistem perundangan sahaja untuk semua rakyat Malaysia(G25 2017: 1) Hasil daripada temubual mendapati G25 berpandangan bahawa kedatangan penjajah telah menerapkan sistem birokrasi Barat dalam pentadbiran negara dan telah menyebabkan wujudnya dua mahkamah. Peranan Mahkamah Sivil dan Mahkamah Syariah awalnya dilihat mempunyai bidang kuasa masing-masing dan tidak mengganggu keharmonian negara dan masyarakat. Namun, masalah mula timbul apabila wujudnya kes-kes tertentu yang melibatkan hal ehwal agama Islam dan mahkamah Syariah tetapi dalam masa yang sama berkait dengan bidang kuasa mahkamah Sivil. Pertindihan ini dilihat menyebabkan berlakunya ketidak adilan kepada individu yang mahu haknya dibela dibawah mahkamah Sivil. G25 menjadikan kes Murtad Lina Joy sebagai contoh bagi menghuraikan situasi pertindihan bidang kuasa antara mahkamah Syariah dan Sivil. Selain itu, dapatan temubual mendapati G25 berpandangan bahawa Mahkamah Syariah sepatutnya membenarkan kelulusan permohonan murtad kerana itu adalah pilihan peribadi pemohon yang memilih untuk keluar dari agama dan mempunyai alasan tersendiri. Mahkamah Syariah tidak perlu menjadikan keputusan kelulusan tersebut sebagai alasan menyebabkan orang ramai akan mengikut jejak langkahnya. Sebaliknya, jabatan dan autoriti agamalah yang perlu mengukuhkan dan memantapkan dakwah kepada umat Islam. Hal ini kerana, bersandarkan kepada ayat dalam al-Quran yang menyatakan bahawa tiada paksaan dalam agama.

\section{Penelitian Semula Tafsiran ke atas Teks-Teks Agama Berkaitan Undang- Undang Islam}

Perlembagaan Persekutuan adalah undang-undang tertinggi negara dan undang- undang lain yang digubal mestilah selari dengannya. Oleh itu, undang-undang Islam di Malaysia juga mestilah tidak boleh bercanggah dengan peruntukan Perlembagaan Persekutuan khususnya perkara berkaitan dengan kebebasan asasi manusia, pembahagian bidang kuasa di antara Kerajaan Persekutuan dan Negeri serta prosedur legislatif. Semua Akta, Enakmen dan undang-undang kecil, termasuk fatwa adalah tertakluk kepada peruntukan Perlembagaan Persekutuan dan terbuka untuk disemak oleh Badan Kehakiman. Berdasarkan hal ini, G25 mendapati kurangnya kesedaran orang ramai, termasuk pemimpin tertinggi terhadap aspek perundangan dan had bidang kuasa institusi agama serta pentadbiran undang-undang Islam di Malaysia (G25 2016:14). 
G25 turut menuntut agar rakyat mempunyai hak untuk membahaskan bagaimana agama Islam patut digunakan sebagai sumber undang-undang dan dasar awam di negara ini. Sumber undangundang Islam adalah daripada panduan al-Quran dan Sunnah, serta usaha manusia (ijtihad) khususnya dalam urusan fiqh dan adat masyarakat. Oleh itu, proses penggubalan undang-undang ini dilihat melibatkan kebijaksanaan dan keputusan oleh manusia biasa. Menurut G25, sumber perundangan Islam yakni al-Quran dan Sunnah sememangnya daripada Tuhan dan suci tetapi hasil enakmen dan keputusan undang-undang adalah perbuatan dan pemikiran daripada manusia. Maka keputusan enakmen undang-undang Islam di Malaysia bukanlah sesuatu yang mutlak malah terbuka untuk dibahaskan dan dipinda supaya matlamat keadilan dapat ditegakkan dalam masyarakat dan bersesuaian mengikut keadaan zaman. G25 turut menyatakan pendirian mereka dalam hal ini seperti berikut (G25 2016:15):

The Islamic Laws of Malaysia are drafted by the Executive arm of goverment and enacted in the Legislative bodies by human beings. Their source may be divine, but the enacted laws are not divine. They are human-made and therefore fallible, open to debate and challenge to ensure that justice is upheld.

Oleh itu, G25 menekankan agar barisan kepimpinan dan berautoriti dapat menghidupkan budaya debat dan wacana yang terbuka dan koheren berhubung dengan pentadbiran undangundang Islam di negara ini ke arah memastikan keadilan dapat dilaksanakan. G25 turut menegaskan bahawa perbahasan secara rasional dan ilmiah tentang undang-undang Islam di Malaysia bukanlah satu penghinaan terhadap Islam dan pihak berkuasa agama di negara ini (G25 2016: 15). Pandangan G25 berkaitan hal ini juga boleh dilihat melalui pendirian Sister In Islam (SIS). SIS menjelaskan bahawa faktor utama kepada krisis kemanusiaan dan perselisihan di kalangan umat Islam disebabkan kefahaman yang salah tentang Islam. Umat Islam selama ini dididik bahawa hanya ada satu sahaja kebenaran iaitu tafsiran dan hukum-hukum yang tersedia dalam kitab-kitab Fiqh klasik dan perlu ditaati jika ingin menjadi Muslim beriman (Indriaty 2012: 96). G25 melihat pandangan dan tafsiran hukum fiqh dan syariah itu sepatutnya mestilah terbuka untuk dinilai semula dan tidak terkurung dibawah kerangka tafsiran klasik dan tradisional untuk memastikan Islam itu bersesuai mengikut arus semasa khususnya apabila konteks dan intipati agama Islam sendiri digunakan dalam pembinaan undang-undang di Malaysia.

\section{Dosa Peribadi Sebagai Satu Jenayah Syariah}

Antara isu utama telah menimbulkan kontroversi adalah berkaitan hukuman oleh pihak berautoriti agama ke atas dosa-dosa atau kesalahan akhlak yang dianggap sebagai peribadi dan tidak menganggu hak orang lain atau menggugat keamanan negara. Oleh sebab itu, G25 menuntut untuk dilakukan penilaian semula ke atas Undang-undang Jenayah Syariah di Malaysia. Undangundang tersebut telah mengkanunkan pelbagai 'dosa peribadi' sebagai satu jenayah dan hal ini telah membawa kepada kekeliruan dan percanggahan dari aspek substantif dan pelaksanaannya. Undang-undang ini bercanggah dengan asas prinsip perundangan Islam dan melanggar hak kebebasan asasi manusia serta menceroboh kehidupan peribadi rakyat (G25 2016: 14). Antara kesalahan undang-undang syariah yang dianggap oleh G25 sebagai dosa peribadi dan pilihan individu serta tidak patut dikategorikan sebagai satu kesalahan jenayah ialah seperti berikut:

1. Transgender: Menurut G25 isu transgender ini merupakan pilihan peribadi seseorang untuk berpakaian mengikut identiti yang dimahukan dalam menjalani kehidupannya. Oleh itu, G25 mengkritik tindakan jabatan agama yang meletakkan denda dan hukuman ke atas kesalahan golongan transgender lelaki yang berpakaian wanita atau sebaliknya (G25 2014: 1). Hal ini dilihat oleh G25 sebagai menyekat kebebasan individu dalam 
mempraktikkan kehidupan yang mereka pilih dan pilihan ini juga dilihat tidak mengganggu atau mengancam keharmonian negara kerana ianya bersifat individu.

2. Khalwat: G25 berpandangan pelaksanaan serbuan khalwat dibawah undang-undang syariah sering menyebabkan sistem keadilan di negara ini dipandang serong. Tindakan JAIS dengan mewujudkan Polis Moral dengan kerjasama PDRM telah menganggu kebebasan peribadi umat Islam. Tambahan lagi, apabila serbuan khalwat ini pernah menyebabkan kecederaan dan kematian dua orang anggota polis semasa mereka cuba mengelak daripada ditangkap khalwat dalam dua serbuan berasingan oleh Jabatan Agama Islam Selangor (JAIS). Kumpulan G25 ini juga melihat tindakan tangkapan khalwat adalah diluar daripada ajaran Islam kerana memberi gambaran bahawa Islam menggunakan hukuman sebagai satu-satunya cara untuk menegakkan nilai moral. Selain itu, G25 juga berhujah bahawa tiada mana-mana negara Arab yang menggunakan polis moral untuk membuat serbuan dan menganggu privasi dalam sesebuah rumah atau bilik hotel bagi mencari pesalah khalwat. Penguatkuasaan penangkapan khalwat dan kepolisan moral juga dilihat sukar dilaksanakan dengan adil kerana kebanyakan pesalah yang menjadi sasaran hanyalah dalam rakyat bawahan sahaja (Mohd 2016: 1). Rententan daripada hal ini, salah seorang ahli G25 telah bersuara dan mencadangkan supaya JAKIM dimansuhkan dan meminta agar aktiviti peribadi orang-orang Melayu Islam juga tidak diganggu oleh mana-mana institusi agama seperti JAKIM yang mengenakan tindakan undang-undang ke atas beberapa dosa peribadi yang dikira tidak mengganggu hak orang lain (Rodelio 2015: 6). Oleh itu, G25 juga menuntut agar Malaysia mengubah pentadbiran Islamnya supaya lebih bertolak ansur dan sesuai dengan gaya hidup moden belia kerana mereka adalah generasi yang akan menerajui negara untuk mencapai kemajuan pada masa akan datang. Penguasaan autoriti agama ke atas undang-undang negara telah mengurangkan ruang untuk berinovasi dan berkreativiti dalam sistem pendidikan dan di tempat kerja disebabkan masyarakat perlu berhati-hati dalam pergaulan seharian mereka antara orang yang berlainan jantina dan ini hanya menyempitkan skop pergaulan antara lelaki dan perempuan. Oleh itu, kita perlu kepada meritokrasi dan hanya dapat dicapai apabila adanya kebebasan peribadi dalam beragama disamping wujudnya faktorfaktor yang lain (Mohd 2016: 1).

3. Denda Makan di Khalayak Ramai Semasa Bulan Ramadhan: G25 bersetuju bahawa orang Islam yang makan di khalayak ramai semasa bulan Ramadhan dianggap tidak menghormati agama dan masyarakat hendaklah sentiasa diingatkan agar menjaga tingkah laku yang sewajarnya dan menghormati Bulan Ramadhan. Meskipun begitu, penangkapan dan denda kepada mereka yang tidak berpuasa kemudian makan di khalayak ramai semasa bulan Ramdhan bukanlah satu solusi yang terbaik. Seharusnya bagi membendung masalah ini semua pihak khususnya autoriti agama mengajar dan mendidik umat Islam mengenai kewajipan agama mereka dan bukan dengan menggunakan hukuman undang-undang. Secara umumnya kita ketahui bahawa dalam masyarakat Muslim pasti wujudnya sesetengah individu yang tidak mendengar nasihat dan melakukan kesilapan. Oleh itu, tidak mematuhi perintah Tuhan haruslah dianggap sebagai perkara peribadi tanpa campur tangan autoriti agama. Hal ini kerana, Malaysia merupakan negara demokratik dan kita perlu jelas bahawa titik asas undang-undang untuk meletakkan sesuatu perbuatan dalam kategori jenayah hanyalah apabila tindakan individu tersebut membahayakan nyawa, harta atau hak dan kebebasan orang lain. Maka, tindakan tidak berpuasa dan makan di khalayak ramai bukanlah satu perbuatan jenayah yang dilakukan ke atas masyarakat yang lain serta tidak menimbulkan risiko keselamatan kepada negara (G25 2017:1). 
Hasil temubual mendapati wujudnya percanggahan pendirian yang berlaku antara ahliahli G25 apabila adanya ahli G25 yang mengeluarkan kenyataan terbuka menuntut agar autoriti agama seperti JAKIM dimansuhkan tetapi sebahagiannya pula menafikan sebaliknya. Informan menjelaskan bahawa G25 tidak menolak autoriti agama di Malaysia cuma mereka tidak menerima dan tidak bersetuju terhadap cara dan pendekatan yang digunakan oleh autoriti agama dalam menghukum dosa-dosa tersebut yang dilihat primitif, kebanyakan pendakwaan dilakukan hanya kepada masyarakat bawahan dan autoriti agama dilihat pernah tersilap semasa melaksanakan tangkapan khalwat yang melibatkan suami isteri. Hal ini menyebabkan G25 tidak mempunyai keyakinan dan kepercayaan terhadap autoriti agama di Malaysia.

\section{Ketidakterbukaan dalam Menerima Perbezaan Aliran dan Pemikiran}

G25 melihat kita perlu mempertingkatkan kesedaran dalam masyarakat khususnya dikalangan pihak autoriti agama sendiri bahawa adanya kepelbagaian pendapat dan pandangan dalam pentafsiran teks agama dan ilmu fiqh. Hal ini termasuklah penelitian semula kaedah-kaedah perundangan yang memungkinkan berlakunya reformasi supaya dapat menegakkan prinsip kesaksamaan dan keadilan yang seiring dan boleh disesuaikan dengan perubahan masa kini. Khususnya dalam aspek tuntutan, peranan dan kedudukan wanita dalam keluarga dan masyarakat (G25 2016: 15). Oleh itu, G25 berpendirian bahawa perbezaan dalam pemikiran dan aliran sama ada daripada pandangan majoriti ataupun minoriti masyarakat Muslim Malaysia hendaklah diraikan. Sekiranya ideologi tersebut menimbulkan kontroversi atau mengelirukan, autoriti agama hendaklah mengadakan perbincangan dan perbahasan secara ilmiah dan bukan dengan menghukum secara undang-undang bagi mereka yang mempunyai pendirian berbeza dengan pendirian pihak autoriti agama sendiri. Hal ini kerana perbezaan pendapat, isu khilafiyah adalah sesuatu yang tidak boleh dielakkan dalam kehidupan bermasyarakat khususnya berkaitan agama.

G25 mengambil contoh berkaitan isu kewajipan pemakaian tudung dan menjelaskan pendiriannya. Menurut G25, terdapat banyak pandangan ulama berkaitan hal ini dan setelah mengkaji dan menelaah pelbagai pandangan tersebut didapati adanya hukum yang meletakkan pemakaian tudung sebagai tidak wajib. Tetapi, disebabkan suasana amalan Islam di Malaysia hanya menjadikan satu pendapat majoriti sahaja sebagai pegangan dan diterima maka pemakaian tudung telah ditetapkan sebagai wajib. Sedangkan menurut G25, apabila ditelusuri sejarah zaman kegemilangan Islam, terdapat pelbagai perbezaan pandangan dalam isu-isu agama dan perbezaan ini disambut baik serta pelbagai perbahasan ilmiah sering dilakukan. Oleh sebab itu Islam mempunyai empat mazhab utama dan bukan satu mazhab sahaja. Namun, G25 turut menegaskan bahawa perkara-perkara yang berkait dengan akidah dan iktikad kepada Allah seperti rukun Islam adalah terkecuali kerana ianya satu ketetapan dan tidak boleh dipersoalkan (Aalia 2016: 1).

Contoh lain dalam menghuraikan tuntutan G25 kepada keterbukaan menerima perbezaan aliran dan pemikiran, ialah kritikan G25 ke atas tindakan JAIS yang membuat serbuan ke atas markas syiah dan menangkap 50 orang penganut syiah semasa sambutan hari Asyura. G25 merujuk kepada Perlembagaan Persekutuan Perkara 11(1) yang menyatakan 'bahawa setiap orang mempunyai hak untuk menganut dan mengamalkan agamanya', dan Artikel 11(4) menyatakan bahawa 'undang-undang Persekutuan boleh mengawal atau menyekat pengembangan apa-apa doktrin atau kepercayaan agama di kalangan orang yang menganuti agama Islam'. Dalam hal berkaitan Syiah, G25 berpendirian bahawa Syiah telah diiktiraf sebagai mazhab yang diterima dalam Islam dan segala bentuk perhimpunan tidak boleh disalah anggap sebagai menyebarkan agama selain Islam kerana Syiah termasuk dalam agama Islam. G25 menjadikan 'The Amman Message' sebagai hujah bahawa Syiah termasuk dalam Islam. The Amman Message ialah dokumen yang ditandatangani di Amman dan diketuai oleh Raja Jordan, Raja Abdullah II, bersama 200 ulama senior di seluruh dunia mewakili aliran pemikiran yang 
berbeza. Dokumen tersebut mengiktiraf semua lapan aliran Islam termasuk Sunni, Syiah, Salafi dan pengikut tasawuf Islam. Oleh itu, pihak berkuasa sepatutnya perlu menggalakkan perbincangan yang harmoni dan intelektual dengan golongan Syiah serta menghormati dan membenarkan perbezaan pendapat. Bukannya menentang mereka melalui hukuman undangundang dan melanggar kebebasan untuk mereka yang mahu mengamalkan ajaran Syiah. Maka, G25 berpandangan bahawa JAIS perlulah maklum bahawa Malaysia adalah sebuah negara bebas demokrasi yang menghormati Perlembagaan Persekutuan sebagai undang-undang tertinggi di negara ini dan perbezaan aliran dalam Islam tidak termasuk dalam perkara yang melanggar Perlembagaan Persekutuan (G25 2016: 1).

Hasil daripada temubual mendapati keterbukaan dalam menerima perbezaan aliran dan pemikiran adalah selagi mana aliran tersebut masih dalam kerangka ajaran Islam yang asas iaitu tidak menolak Allah sebagai Tuhan dan Nabi Muhammad SAW sebagai Rasul-Nya. Dalam keduadua isu, kajian merumuskan informan menggunakan justifikasi bahawa beberapa pendirian G25 berkaitan perkara agama yang dianggap berbeza dari pandangan awam bukanlah daripada pandangan peribadi yang dibuat sewenang-wenangnya tetapi mereka juga turut bersandarkan kepada pandangan para ulama. G25 mahu agar pihak berautoriti agama menerima bahawa adanya perbezaan pendapat dalam kalangan ulama walaupun pandangan itu hanya daripada minoriti ulama, namun ianya masih lagi dikira sebagai pandangan yang boleh dipegang dan diterima.

Berdasarkan daripada huraian di atas, kajian mendapati isu, tuntutan dan justifikasi yang dikemukakan oleh kumpulan G25 mempunyai persamaan dengan pembawaan aliran Islam Liberal. Tambahan lagi, salah seorang ahli G25 turut mengakui bahawa pemikirannya adalah liberal namun dalam masa yang sama beliau juga menyatakan bahawa beliau adalah seorang Muslim yang komited dalam agama. Menurutnya definisi liberal ialah keterbukaan menerima perbezaan pendapat dan pluralis adalah keterbukaan menerima perbezaan agama. Asasnya adalah menghormati antara satu sama lain (Aalia 2016: 1). Oleh itu, kajian mendapati bahawa kumpulan G25 membawa aliran pemikiran liberal namun kumpulan ini menegaskan bahawa dalam ideologi dan perjuangan mereka bukanlah menolak autoriti agama apatah lagi agama Islam itu sendiri. Mereka memperjuangkan agar agama Islam dan pelaksanaan undangundangnya di Malaysia dapat mengikut kerangka kesederhanaan (moderate) mereka iaitu meraikan semua pendapat dan perbezaan tanpa terkecuali, tidak menjatuhkan hukuman undangundang atas dosa-dosa peribadi tetapi memperkukuhkan dakwah kepada masyarakat, menegakkan keadilan dengan membela hak asasi dan persamaan antara manusia.

Hasil daripada temubual turut mendapati faktor kritikan G25 ke atas autoriti agama adalah seperti berikut:

1. Pendakwaan Terpilih (Selective Prosecution: G25 melihat pihak autoriti agama mengenakan tindakan undang-undang hanya kepada orang-orang tertentu khususnya dikalangan masyarakat bawahan. Tetapi apabila ianya melibatkan orang atasan ataupun mempunyai kaitan dengan kepentingan politik, tiada tindakan yang dikenakan kepada mereka berkaitan undang-undang Islam seperti tangkapan khalwat. Oleh itu, G25 melihat adanya pilih kasih dan double-standart oleh pegawai autoriti agama dalam menjalankan tugas mereka.

2. Prosedur Yang Bersifat Autoritatif dan Tidak Mesra Masyarakat: G25 berpandangan prosedur dan pendekatan pihak autoriti agama di Malaysia lebih bersifat menghukum daripada mendidik masyarakat sedangkan agama Islam adalah agama yang membawa rahmat dan kasih sayang. Hasil daripada temubual, kajian mendapati berlakunya pengulangan istilah yang tinggi berkaitan teokrasi dan autokrasi agama. Hal ini menggambarkan G25 melihat autoriti agama di Malaysia bersifat terlalu berkuasa ke atas masyarakat. 
Secara keseluruhannya, kritikan dan isu-isu yang disuarakan oleh G25 mempunyai justifikasi yang melibatkan pengalaman peribadi semasa berurusan dengan pegawai agama itu sendiri dan sebahagiannya adalah pandangan umum ke atas isu-isu agama yang dikendalikan oleh autoriti agama. G25 melihat autoriti agama di Malaysia mempunyai pengaruh kuasa yang begitu besar sehingga sebahagian tindakan undang-undangnya dilihat ada yang bercanggah dengan peruntukan Perlembagaan Persekutuan. Oleh itu, bagi mengelakkan autoriti agama di Malaysia melebihi bidang kuasanya, G25 mengeluarkan kritikan dan tuntutan tersebut untuk diteliti semula khususnya oleh pihak autoriti agama sendiri.

Berdasarkan penjelasan prinsip di atas, kajian mendapati terdapat kekeliruan pandangan oleh G25 yang menyatakan pendiriannya dalam usaha menegakkan Islam dengan menjaga Maqasid Syariah namun dalam masa yang sama cuba membatasi atau mempertikaikan kuasa autoriti agama dalam hal ini. Kekeliruan ini akhirnya menimbulkan beberapa persoalan berkaitan apakah Maqasid Syariah yang cuba mereka sempurnakan dan apakah ciri-ciri dan kumpulan yang layak menentukan Maqasid Syariah tersebut. Dalam konteks Islam, kita telah maklum bahawa penentuan kayu ukur dan prinsip maqasid bukanlah sesuatu yang boleh ditentukan oleh individu tertentu sewenang-wenangnya. Namun, memerlukan kepada kumpulan yang berkelayakan dan pakar dalam hal ehwal hukum dan mazhab. Hal ini bertujuan bagi mengelakkan penentuan maqasid yang bersifat untuk kepentingan peribadi dan individualistik kerana perkara ini boleh mengakibatkan lahirnya kenisbian nilai (nilai yang bersifat relatif dan boleh menjadi ancaman kepada sesuatu tamadun) dalam sistem perundangan syariah khususnya di Malaysia. Oleh itu, kajian menunjukkan bahawa G25 tidak menolak autoriti agama di Malaysia secara total tetapi mahukan autoriti agama yang longgar atas beberapa perkara yang boleh diselarikan dengan hak asasi dan kebebasan manusia. Selain itu, kajian memahami bahawa G25 menekankan kepada kebebasan dalam memperluaskan pentafsiran teks agama dan tidak terikat pada pandangan satu pihak sahaja. Sebagai contoh, hanya pandangan yang ditetapkan oleh autoriti agama sahaja yang boleh diamalkan dan diterima. Sedangkan, adanya pandangan-pandangan lain yang dikira lebih moden dan mengikut kehendak semasa. G25 dilihat jelas mengetahui bahawa mereka bukan ahli agama atau pakar dalam bidang agama, oleh sebab itu justifikasi yang diberikan oleh G25 turut disandarkan kepada pandangan ulama yang didakwa sama dengan pandangan mereka sedangkan padangan tersebut adalah pandangan terpencil (bukan secara jumhur). Oleh itu, kajian merumuskan tuntutan dan justifikasi yang diberikan oleh G25 dilihat sebagai satu usaha kepada proses liberalisasi agama di Malaysia yang mana melalui kaca mata usaha liberalisasi ini, Islam akan dilihat lebih terbuka, tidak ortodoks dan menyeluruh dalam membela umat manusia kerana dilihat sesuai sepanjang zaman dan tempat mengikut kehendak manusia.

Islam sebenarnya telah menjelaskan kepentingan autoriti agama dengan jelas mengenai konsep khilafiyah khususnya berkaitan isu-isu fiqh dan perundangan. Penekanan kefahaman berkaitan konsep penetapan hukum amatlah perlu seperti Sadd al-Zara'i dan Masalih al-Mursalah dan sebagainya bagi memahami justifikasi perundangan dan enakmen syariah yang telah ditetapkan. Meskipun pentafsiran ulama klasik dianggap bukanlah satu pandangan mutlak, tetapi pandangan dan ijtihad mereka telah menjadi panduan kepada jumhur ulama Islam masa kini. Antara sebabnya adalah kerana kekuatan periwayatan dan sanad ilmu adalah daripada ulama Salaf dan Khalaf sendiri, dekatnya zaman mereka dengan zaman Rasulullah SAW dan ketatnya syarat dan disiplin ilmu yang mereka letakkan dalam pentafsiran al-Quran dan hadis agar penafsiran tidak dibuat sesuka hati dan sewenang-wenangnya. Oleh itu, pandangan ulama muktabar klasik tidak boleh diketepikan dan tidak diambil kira.

Seterusnya, penafian kepada peranan autoriti agama hakikatnya menggangu pelaksanaan konsep Amar Ma'ruf dan Nahi Munkar. Kita telah jelas dalam Sirah Nabawi bahawa urusan Amar $M a ' r u f$ ini telah pun berjalan secara berperingkat merangkumi pendidikan tazkiyah nafs bermula daripada tindakan peribadi individu sendiri, usaha dalam institusi keluarga dan masyarakat serta perundangan yang mana secara tidak langsung telah melibatkan autoriti agama. Hal ini kerana, 
Islam merupakan agama yang lengkap dan fleksibel. Oleh itu, selain daripada menyeru dan berdakwah kepada kebaikan dengan kasih sayang (Amar Ma'ruf), Islam juga mempunyai prinsip menolak kejahatan dan kemungkaran dosa (Nahi Mungkar) dalam kalangan masyarakat Muslim. Namun, kedua-dua prinsip ini perlu kepada pendekatan hikmah dan kemahiran dakwah yang baik untuk menyantuni dan menyebarkan kefahaman Islam kepada orang ramai. Dakwah secara hikmah bukan sekadar bererti melalui pendekatan kelembutan dan ajakan semata-mata, pendekatan hikmah bermaksud dakwah mengikut kesesuaian keadaan yang mana ada ketika dilakukan secara lembut dan santai seperti dakwah melalui akhlak, dan ada ketikanya perlu juga kepada penegasan dan tindakan kuasa undang-undang Islam. Dalam masa yang sama, pelaksanaan undang-undang Islam itu perlulah dilakukan dengan amanah dan terperinci agar hak-hak asasi dan keadilan orang Islam itu sendiri dapat dibela dan kerosakan dapat dielakkan. Oleh itu, autoriti agama juga diperlukan bagi melaksanakan undang-undang Syariah di Malaysia dan bukan sekadar menjalankan kerja-kerja dakwah berbentuk ceramah dan seminar sematamata. Akhir sekali, jelasnya kita juga perlulah menerima dan menghormati bahawa Perkara 3 telah mengisytiharkan Islam sebagai agama negara dan tiadanya penyataan bahawa Malaysia adalah negara sekular dalam Perlembagaan Persekutuan. Tambahan lagi, perkara tersebut bukanlah sekadar satu pandangan tetapi telah pun termaktub dalam teks Perlembagaan Perkara 3 bahawa Islam sebagai agama Persekutuan, oleh itu undang-undang Syariah dan Sivil yang dilaksanakan kesemuanya harus selaras dengan prinsip Islam sebagai agama negara.

Kesimpulannya, penafian hak dan kewujudan autoriti agama boleh mengakibatkan kemusnahan nilai akhlak dan kehidupan masyarakat Islam namun bukanlah bermakna pihak berautoriti agama boleh melakukan perbuatan 'ambil kesempatan' demi kepentingan peribadi dan individu tertentu kerana perbuatan ini sendiri adalah zalim kepada masyarakat dan khianat kepada agama. Sejarah kedatangan agama dalam masyarakat Islam sendiri amatlah berbeza dari pandangan agama yang lain. Hal ini kerana, Islam datang kepada masyarakat yang sedang berada dalam keadaan tertindas dan jahiliyah. Maka sejarah membuktikan bahawa Islam dan kumpulan autoriti agama telah memainkan peranan dalam menaikkan martabat, maruah dan intelektual penganutnya. Oleh itu, tujuan ini perlu dikekalkan dengan menjaga prinsip dan amanah yang sama khususnya di kalangan mereka yang berada di dalam autoriti agama dan masyarakat Islam secara amnya bagi mengelakkan masyarakat kembali kepada kejahilan.

\section{Acknowledgement}

Research Grant GGPM-2017-018, Universiti Kebangsaan Malaysia.

\section{References}

Aalia al-Hadjri. 2016. Manifestations of Religious Intolerance Worries Woman Behind $\quad$ G25. https://www.g25malaysia.org/single post/2016/04/17/Manifestations-of-religiousintolerance-worries-woman behind-G25 [12 July 2017].

Abdul Munir Yaacob. 2009. Pelaksanaan perundangan Islam di Malaysia: satu penilaian. Jurnal Fiqh. 6: 1-20.

Azmi Sharom. 2016. Fundamental liberties in the Federal Constitution. In G25 Malaysia (ed.). Breaking the Silence: Voices of Moderation, pp. 94-102. Singapore: Marshall Cavendish Editions.

G25. 2014. Champion Open Debate and Discourse on Islamic Law. https://www.g25malaysia.org/single-post/2014/01/19/How-to-Make-Your- OfficeMore-Efficient [28 March 2017].

G25. 2016. Breaking The Silence Voices of Moderation. Singapore: Marshall Cavendish.

G25. 2016. Islam in A Constitutional Democracy, A G25 Public Forum Programme Summary of Topics Discussed. https://docs.wixstatic.com/ugd/471d06_9685434915734d3c871dde9 
d61e8a690.pdf [20 June 2017]

G25. 2016. Malaysian Leaders Reminded of Amman Message On Shias. http://www.freemalaysiatoday.com/category/nation/2016/10/17/msia n- leadersreminded-of-amman-message-on-shias/ [20 June 2017].

G25. 2016. Kafir Harbi Remarks a Threat. http://www.thestar.com.my/news/nation/2016/06/30/kafir-harbi- remarks-a- threatg25-it-is-similar-to-is-dangerous-ideology/ [20 June 2017].

G25. 2016. A Freedom Under Constitution. http://www.thestar.com.my/opinion/letters/2016/10 /18/a-freedom- under- constitution/ [20 June 2017].

G25. 2017. G25 Beri 5 Sebab Jangan Sokong Usul Hadi. http://www.freemalaysiatoday.com/category/bahasa/2017/03/06/g25-beri-5- sebabuntuk-tidak-sokong-usul-hadi/ [20 June 2017].

G25. 2017. Malaysians Must Stand Firm Against RUU355, Says G25. http://www.thestar.com.my/news/nation/2017/05/03/malaysians- must- stand- firmagainst-ruu355-says-g25-hadis-bill-a-back-door-way-of- imposing-hudud-onp/\#7QhXwwPf3sfsdKIl.01 [20 June 2017].

G25. 2017. The Role of Religious Department. https://www.g25malaysia.org/singlepost/2017/06/02/The-role-of- religious- departments [20 June 2017].

G25. 2017. Autoriti Agama Menurut Perspektif G25, Shah Alam. Interview, 4 July.

Indriaty Ismail. 2012. ciri-ciri dan asas utama Islam liberal dalam pergerakan Sisters in Islam. Dlm. Mazlan Ibrahim, Latifah Abdul Majid \& Fadlan Mohd Othman (eds.). Islam Liberal Isu Dan Reaksi, pp. 90-106. Selangor: Jabatan Agama Islam Selangor.

Marzuki Mohamad. 2009. Manifestasi Islam liberal di Malaysia: Dimensi Politik dan UndangUndang. Dlm. Abdul Karim Ali \& Mohd Roslan Mohd Nor (eds.). Islam Liberal Isu dan Cabaran. hlm. 157-176. Petaling Jaya: Persatuan Ulama' Malaysia.

Mahamad Nasir Disa. n.d. Islam Agama Negara: Undang-Undang Tertinggi Negara. http://www.arkib.gov.my/documents/10157/a76af809-88b4-4b61-9984 61cb6b4d2c9d [29 March 2017].

Mariam Mokhtar. 2015. Noor Farida Ariffin, A Catalyst for Change. http://www.freemalaysiatoday.com/category/highlight/2015/05/15/noor-faridaariffin-a-catalyst-for-change/ [29 March 2017].

Mohamad Hafiz Yusuf Bakri. 2015. G25 Aibkan Kumpulan Sendiri. http://www.utusan.com.my/berita/nasional/g25-aibkan-8232-kumpulan sendiri1.165965 [29 March 2017].

Malaysia. 1963. Undang-Undang Perlembagaan Persekutuan Malaysia.

Mohd Sheriff Mohd Kassim. 2016. Sheriff Kritik Tangkapan Khalwat, Polis Moral. http://m.malaysiakini.com/news/366423 [20 June 2017].

Mohd Sheriff Mohd Kassim. 2016. Jais Raids Show Muslims Have Less Freedom. http://www.themalaymailonline.com/what-you-think/article/jais-raids- show-muslimshave-less-freedom-mohd-sheriff-mohd-kassim [20 June 2017].

Nazri Muslim \& Ahmad Hidayat Buang. n.d. Islam dalam Perlembagaan Persekutuan dari perspektif hubungan etnik di Malaysia. Jurnal Kemanusiaan. 20: 115-129.

Rodelio Junjun Taucan. 2015. G25 Mahu hukuman khalwat dimansuh. Utusan Malaysia, 7 December: 6. 